Case

\title{
Totally Arterial Off-pump Coronary Artery Bypass Grafting after Pneumonectomy
}

\author{
Teruaki Ushijima, MD, PhD, Yujiro Kikuchi, MD, PhD, Chikako Ikeda, MD, \\ Munehisa Takata, MD, PhD, Yoshitaka Yamamoto, MD, and Go Watanabe, MD, PhD
}

\begin{abstract}
We report the case of an 82-year-old man who underwent triple coronary artery bypass grafting with arterial grafts, who 20 years previously underwent left pneumonectomy for lung cancer. Computed tomography (CT) presented a marked shift of the heart and great vessels into the left hemithorax. Off-pump coronary artery bypass grafting was performed through a left thoracotomy, in which the left internal thoracic, right gastroepiploic, and radial arteries were used. He was extubated 1 hour post-operatively and had an uneventful recovery.
\end{abstract}

Key words: off-pump surgery, CABG, arterial grafts, pneumonectomy

\section{Introduction}

Coronary artery bypass grafting (CABG) in patients with prior pneumonectomy is a challenge. The surgeon, before deciding on the surgical strategy, should consider anatomical changes such as an extreme anatomical shift of the heart as well as decreased pulmonary function and procedural aspects of the surgery. We describe a case of a total arterial off-pump, coronary revascularization that was performed many years after a pneumonectomy.

\section{Case Report}

An 82-year old man with a history of left pneumonectomy for lung cancer 20 years prior to presentation was admitted to our institute for the treatment of an abdominal aortic aneurysm. Because his electrocardiogram and myocardial scintigraphy showed inferior myocardial

Division of Cardiac Surgery, Tokyo Medical University, Tokyo, Japan

Received: January 4, 2010; Accepted: March 15, 2010

Corresponding author: Teruaki Ushijima, MD, PhD. Division of Cardiac Surgery, Tokyo Medical University, 6-7-1 Nishishinjuku, Shinjuku-ku, Tokyo 160-0023, Japan

Email: ushijima@tokyo-med.ac.jp

(C)2011 The Editorial Committee of Annals of Thoracic and Cardiovascular Surgery. All rights reserved. infarction and anterior ischemia, we performed coronary angiography, which confirmed triple-vessel disease with chronic occlusion of the right coronary artery and left anterior descending artery, and severe stenosis of the posterolateral artery. Arterial blood gas levels at rest were normal $\mathrm{pH}$ (7.40), $\mathrm{PaO}_{2}(85.3 \mathrm{mmHg})$ and $\mathrm{PaCO}_{2}$ (43.2 $\mathrm{mmHg}$ ). A pulmonary function test showed moderate restrictive and obstructive respiratory dysfunction. The forced expiratory volume in 1 second and the forced vital capacity were $1.28 \mathrm{~L}$ and $1.89 \mathrm{~L}(63.8 \%$ of predicted value), respectively. Chest radiography and computed tomography (CT) presented a marked shift of the heart and the great vessels into the left hemithorax with a hyperinflated right lung crossing the midline (Fig. 1). The patient was scheduled to undergo CABG prior to AAA repair.

Under a general anesthesia in a right semi-decubitus position, the left thoracic cavity was entered through the fifth intercostal space. The left internal thoracic artery (LITA) was harvested and the radial artery graft was anastomosed to it in end-to-side fashion, creating a Y-composite graft. The right gastroepiploic artery (RGEA) was harvested through a small upper laparotomy incision with skeletonization. The radial artery was anastomosed to the RGEA in end-to-end fashion as a composite straight graft. The RGEA composite graft was passed through the diaphragm and positioned behind the 


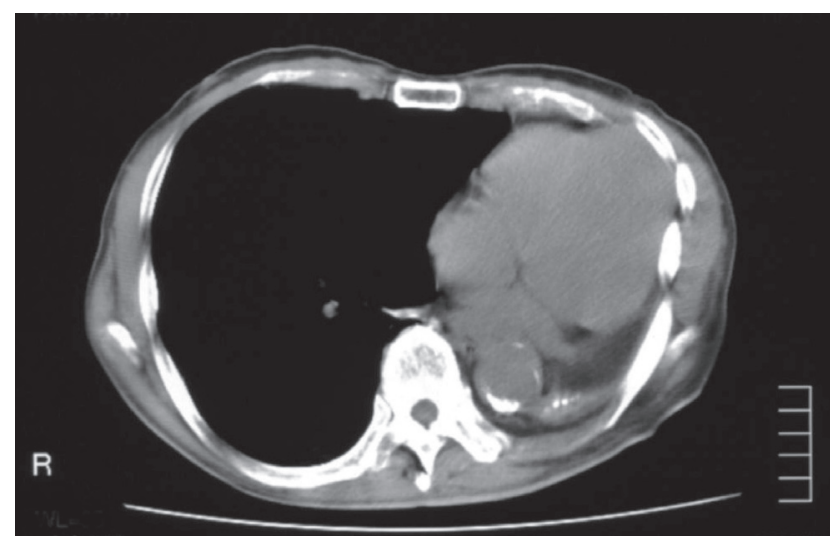

Fig. 1 Preoperative computed tomography of a marked shift of the heart and the great vessels into the left hemithorax with a hyperinflated right lung crossing the midline.

heart. The visualization of the target vessels was easy and off-pump coronary artery bypass grafting (OPCAB) technique was used. The LITA and branched radial artery were grafted to the left anterior descending artery and to the posterolateral artery, respectively. The RGEA composite graft was anastomosed to the posterodescending artery. Throughout the procedure, the patient's condition was stable without any inotropic support.

He was extubated one hour postoperatively and had an uneventful postoperative recovery (Fig. 2). CT coronary angiography revealed that the grafts were all patent (Fig. 3). He underwent AAA repair successfully two months after OPCAB.

\section{Discussion}

CABG is a challenge in patients with prior pneumonectomy, because of the decreased pulmonary function and anatomical shift of the heart. It is well known that the use of cardiopulmonary bypass negatively affects pulmonary function. Especially in patients with prior pneumonectomy, postoperative pulmonary complications are often fatal. In a recent review by Stoller et, al the mortality and morbidity rate of CABG with cardiopulmonary bypass were $30.8 \%$ ( 4 of 13 patients) and $46.2 \%$ (6 of 13 patients), respectively. ${ }^{1)}$ All the complications, except for 1 case of stroke, were respiratory insufficiency such as reintubation or pneumothorax. However, offpump CABG reduces postoperative pulmonary dysfunction and improves operative results. ${ }^{2)}$ Six cases of OPCAB have been reported in patients with prior pneumonectomy., ${ }^{1-6)}$ Including the current case, all cases recovered well without any major complications. OPCAB

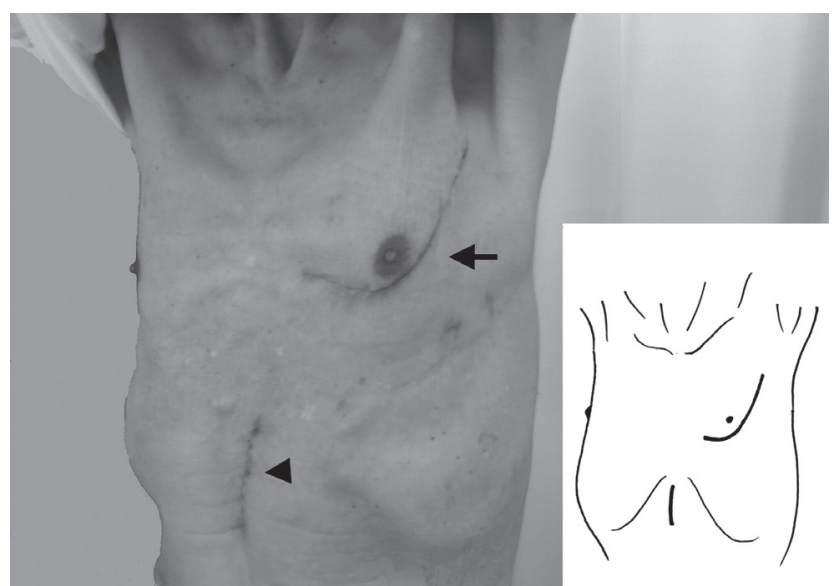

Fig. 2 Skin incisions. Left thoracotomy (arrow) and small upper laparotomy incision (arrow head).

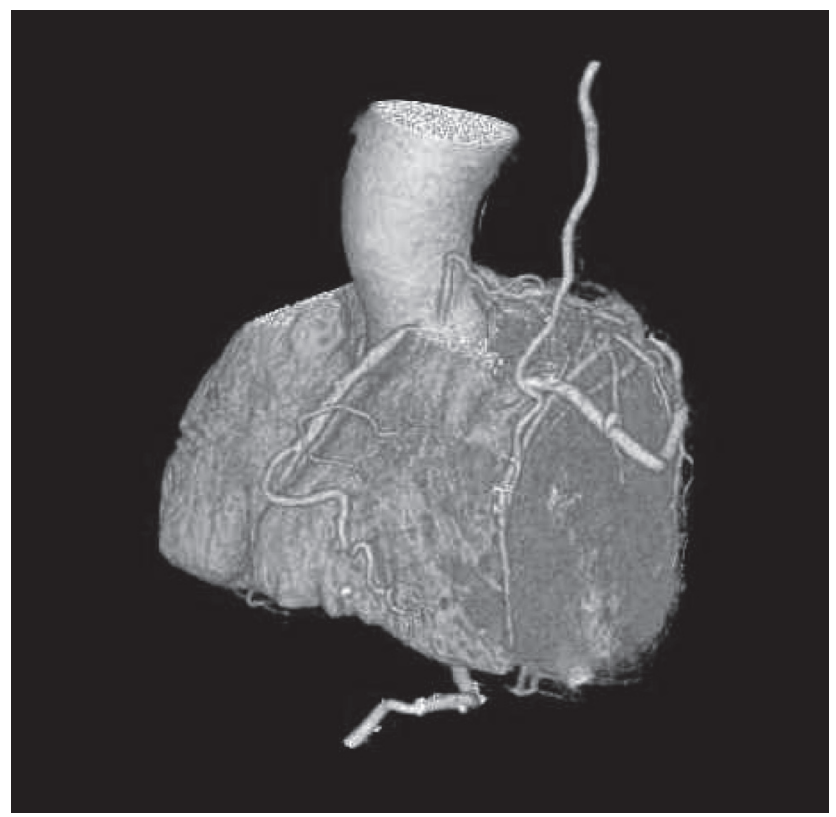

Fug. 3 Postoperative computed tomography coronary angiography of patent grafts.

should be performed to avoid pulmonary complications in patients with prior pneumonectomy.

After pneumonectomy, there is a marked mediastinal shift towards the vacated pneumonectomy space. Following left pneumonectomy, access to arteries in the circumflex region becomes difficult through median sternotomy. If OPCAB is to be performed, we do not need to access the central venous system for the preparation of cardiopulmonary bypass, and we can determine the operative strategy as we preferentially consider the accessibility to target coronary vessels. In latest 3 of 6 reported OPCAB cases, left thoracotomy was selected in patients with prior 
Table 1 Clinical data of patients with pneumonectomy who underwent OPCAB

\begin{tabular}{|c|c|c|c|c|c|}
\hline Author/ Year & $\begin{array}{l}\text { Age (years) / } \\
\text { sex }\end{array}$ & $\begin{array}{c}\text { Site of } \\
\text { pneumonectomy }\end{array}$ & Approach & $\begin{array}{l}\text { Type of graft } \\
\text { conduits }\end{array}$ & $\begin{array}{c}\text { Target coronary } \\
\text { vessels }\end{array}$ \\
\hline \multirow{2}{*}{$\begin{array}{r}\text { El-Hamamsy et al. }{ }^{3)} / 2003 \text { patient2 } \\
\text { patient3 }\end{array}$} & $71 / \mathrm{F}$ & Right & Sternotomy & $3 \mathrm{SV}$ grafts & \\
\hline & $73 / \mathrm{M}$ & Right & Sternotomy & LITA, 2 SV grafts & \\
\hline Kumar et al. ${ }^{4} / 2003$ & $70 / \mathrm{M}$ & Left & Sternotomy & LITA, SV graft & LAD, PD \\
\hline Bernet et al. ${ }^{5 /} / 2006$ & $58 / \mathrm{M}$ & Right & Sternotomy & LITA, SV graft & LAD, OM \\
\hline Stoller et al. ${ }^{1 /} / 2007$ & $54 / \mathrm{F}$ & Left & Thoracotomy & SV graft & $\mathrm{LAD}, \mathrm{CX}$ \\
\hline Zhao et al. ${ }^{6} / 2008$ & $57 / \mathrm{M}$ & Left & Thoracotomy & $2 \mathrm{SV}$ grafts & LAD, RCA, OM \\
\hline Current report & $82 / \mathrm{M}$ & Left & Thoracotomy & LITA, RA, RGEA & LAD, PL, PD \\
\hline
\end{tabular}

CX, left circumflex artery; LAD, left anterior descending artery; LITA, left internal thoracic artery; OM, obtuse marginal branch; PD, posterior descending artery; PL, posterolateral artery; RA, radial artery; RCA, right coronary artery; RGEA, right gastroepiploic artery; SV, saphenous vein

left pneumonectomy (Table 1). However, the present case was the only one to use the LITA. All other cases used saphenous veins, and the proximal anastomoses were performed to the ascending aorta and the descending aorta. Because it was possible to use the LITA through a sternotomy in the patient with prior left pneumonectomy, it was possible to use LITA with adequate harvesting proximally through a thoracotomy. Our group reported the technique of multivessel OPCAB using arterial grafts through a thoracotomy a decade ago. ${ }^{7)}$ The usage of insitu arterial grafts does not require aortic manipulation. By applying this technique, we could minimize perioperative complications and achieve a favorable outcome for the patient.

\section{References}

1) Stoller JK, Blackstone E, Pettersson G, Mihaljevic T. Coronary artery bypass graft and/or valvular operations following prior pneumonectomy: report of four new patients and review of the literature. Chest 2007; 132: 295-301.
2) Raja SG, Berg GA. Impact of off-pump coronary artery bypass surgery on systemic inflammation: current best available evidence. J Card Surg 2007; 22: 445-55.

3) El-Hamamsy I, Stevens LM, Perrault LP, Carrier M. Right pneumonectomy and thoracoplasty followed by coronary artery bypass grafting and mitral valve replacement. J Thorac Cardiovasc Surg 2003; 125: 215-6.

4) Kumar P, Swift SJ, Athanasiou T, Nelson JS, Glenville B. CABG 15-years after left pneumonectomy: feasibility of off-pump approach. Cardiovasc Surg 2003; 11: 305-7.

5) Bernet FH, Reineke DC, Grapow MT, Zerkowski HR. OPCAB surgery after right pneumonectomy. J Card Surg 2006; 21: 92-3.

6) Zhao BQ, Chen RK, Song JP. Coronary artery bypass grafting after pneumonectomy. Tex Heart Inst J 2008; 35: 470-1.

7) Watanabe G, Misaki T, Kotoh K, Kawakami K, Yamashita A, et al. Multiple minimally invasive direct coronary artery bypass grafting for the complete revascularization of the left ventricle. Ann Thorac Surg 1999; 68: 131-6. 